\title{
Nonlinear Control of Hydrostatic Thrust Bearing Using Multivariable Optimization
}

\author{
Waheed Ur Rehman ${ }^{1,2} \mathbb{D}^{\text {, Wakeel Khan }}{ }^{2}$, Nasim Ullah ${ }^{3}{ }^{-}$, M. D. Shahariar Chowdhury ${ }^{4,5}$, \\ Kuaanan Techato ${ }^{4,5, *(1)}$ and Muhammad Haneef ${ }^{2}$ \\ 1 College of Mechanical Engineering and Applied Electronics Technologies, Beijing University Technology, \\ Beijing 100124, China; wrehman87@bjut.edu.cn \\ 2 Department of Electrical Engineering, Foundation University Islamabad, Islamabad 44000, Pakistan; \\ Wakeel.khan@fui.edu.pk (W.K.); muhammadhaneef@fui.edu.pk (M.H.) \\ 3 Department of Electrical Engineering, College of Engineering, Taif University, Taif 21944, Saudi Arabia; \\ nasimullah@tu.edu.sa \\ 4 Faculty of Environmental Management, Prince of Songkla University, Hat Yai 90110, Thailand; \\ mdshahariar.c@psu.ac.th \\ 5 Environmental Assessment and Technology for Hazardous Waste Management Research Center, Faculty of \\ Environmental Management, Prince of Songkla University, Hat Yai 90110, Thailand \\ * Correspondence: kuaanan.t@psu.ac.th
}

check for updates

Citation: Rehman, W.U.; Khan, W.; Ullah, N.; Chowdhury, M.D.S.;

Techato, K.; Haneef, M. Nonlinear Control of Hydrostatic Thrust Bearing Using Multivariable Optimization. Mathematics 2021, 9, 903. https:// doi.org/10.3390/math9080903

Academic Editor: William Guo

Received: 5 March 2021

Accepted: 7 April 2021

Published: 19 April 2021

Publisher's Note: MDPI stays neutral with regard to jurisdictional claims in published maps and institutional affiliations.

Copyright: (c) 2021 by the authors. Licensee MDPI, Basel, Switzerland. This article is an open access article distributed under the terms and conditions of the Creative Commons Attribution (CC BY) license (https:/ / creativecommons.org/licenses/by/ $4.0 /)$.

\begin{abstract}
This research work is focused on the nonlinear modeling and control of a hydrostatic thrust bearing. In the proposed work, a mathematical model is formulated for a hydrostatic thrust bearing system that includes the effects of uncertainties, unmodelled dynamics, and nonlinearities. Depending on the type of inputs, the mathematical model is divided into three subsystems. Each subsystem has the same output, i.e., fluid film thickness with different types of input, i.e., viscosity, supply pressure, and recess pressure. An extended state observer is proposed to estimate the unavailable states. A backstepping control technique is presented to achieve the desired tracking performance and stabilize the closed-loop dynamics. The proposed control technique is based on the Lyapunov stability theorem. Moreover, particle swarm optimization is used to search for the best tuning parameters for the backstepping controller and extended state observer. The effectiveness of the proposed method is verified using numerical simulations.
\end{abstract}

Keywords: multivariable optimization; numerical modeling; hydrostatic thrust bearing; membrane restrictor; servo control systems; backstepping control; extended state observer

\section{Introduction}

Enhanced lubrication performance of mechanical bearings ensures high reliability and accuracy of the machining process. In this regard, several studies have reported on the improvement of lubrication performance by utilizing the optimization of bearing geometry [1-3]. The geometry optimization of bearings allows a one-time improvement in the lubrication performance of the hydrostatic bearing because once a system has been designed, then the mechanical design cannot be altered easily. Thus, the enhancement of lubrication performance by other means is preferred over mechanical design. Active hydrostatic bearings have a sort of active device that improves lubrication performance. The active device helps to increase the stiffness of the fluid film; more stiffness means an increase in bearing load capacity. Broadly speaking, the active hydrostatic bearings are divided into three configurations. This division is done on the basis of an active input that is used to control the dynamics of hydrostatic bearings.

The first configuration takes viscosity as a control input for active lubrication. Hesselbach [4], Wang [5], and Zhang [6] used magnetorheological fluids (MR fluids) to provide active lubrication in hydrostatic bearings by utilizing an external magnetic field. This field changes the viscosity of magnetorheological fluids to maintain a constant fluid film gap 
by varying the load. The biggest problem with MR-fluid-based hydrostatic bearings is their support for small loads. Large loads can only be supported by increasing the support area. Normally, the MR-fluid-based hydrostatic bearings are called smart bearings. Kumar [7] used a combination of both recess shape and magnetorheological fluids to provide active lubrication.

The second configuration takes recess pressure as a control input to monitor the clearance gap. Morosi [8] and Fabian [9] proposed a jet to control the pressure between the rotating shaft and the bearing's inner surface. This jet controls recess pressure, and it is driven by a piezoelectric-type actuator. Mizumoto [10] proposed an active orifice to control recess pressure. Rehman [11-14] proposed a controlled servo valve to adjust recess pressure. Eberhardt [15] measured the clearance gap with the help of an eddy current sensor; hydrostatic support is activated when the clearance gap is critical. Rehman [16] proposed an active aerostatic thrust bearing, where high-speed pneumatic valves are used to control recess pressure and adjust fluid film thickness. Kang [17,18] proposed different types of restrictors to control recess pressure. Tapered-spool-type and cylindricalspool-type double-action restrictors have been proposed for the variable compensation of hydrostatic bearings. Recently, Babin [19] performed an experimental study where a servo-controlled thrust bearing was proposed to improve dynamic stiffness against an external load. Lai [20] used a membrane-type restrictor that controls active lubrication through recess pressure.

The third configuration provides active lubrication with the help of active supply pressure, which is taken as a control input. Santos [21] proposed a hydraulic actuator to control supply pressure. A hydraulic actuator helps increase the damping and stiffness of oil film. San Andrés [22] proposed an external pressure source to stiffen the fluid film for gas bearings. The increase in stiffness of the fluid film helps to reduce the vibrations of the rotor and increases stability.

From the above-cited literature, it has been concluded that tribology, control techniques, and the informatics of bearings play important roles in improving active lubrication. A frequency-domain control method was reported in [21] for active lubrication of a bearing; however, the classical design method neglects several control features, such as parametric uncertainties, unmodeled dynamics, and nonlinearities. Similarly, a nonlinear control method was reported for active lubrication in [23], while a linear observer-based control method was proposed in [24]. However, the nonlinear controller proposed in [23] is dependent on the calculation of the unknown terms $\mathrm{f}(\mathrm{x})$; in practical cases, its nominal values are known. This paper proposes a backstepping combined extended-state observer-based control scheme for active lubrication of hydrostatic bearings. The current research proposal has two main advantages over the published literature in [23]: (1) The proposed mathematical model includes the effects of nonlinearities, uncertainties, and unmodelled dynamics; thus, it can be implemented in real-world applications. Secondly, the combination of backstepping control and extended state observer helps to achieve better tracking performance. The proposed control scheme requires few sensors to monitor the system states; thus, it is cost-effective and more economical. Specific objectives of this work are highlighted as follows:

1. The proposed method utilizes an extended state observer to estimate the unknown terms in the state models of the system.

2. The combined extended-state-observer-based backstepping controller is an adaptive type compared to the previously reported method of [23].

3. The optimal parameters of the proposed control scheme are tuned using the multiobjective particle swarm optimization method, while in the previously reported literature, the criteria for parameters tuning is not given.

4. As compared to previously reported methods, the proposed method utilizes fewer sensors to implement the control law.

The rest of the paper is organized as follows: Section 2 formulates the mathematical models for hydrostatic thrust bearings, Section 3 designs an extended-state-observer-based 
backstepping control that is tuned with the help of particle swarm optimization, Section 4 describes the results, and, finally, a conclusion is made in Section 5.

\section{Mathematical Models}

\subsection{Fluid Viscosity as Control Input}

Figure 1 shows a thrust bearing whose viscosity is taken as a control input. Normally, a magnetic field is applied to change the viscosity of such types of bearing.

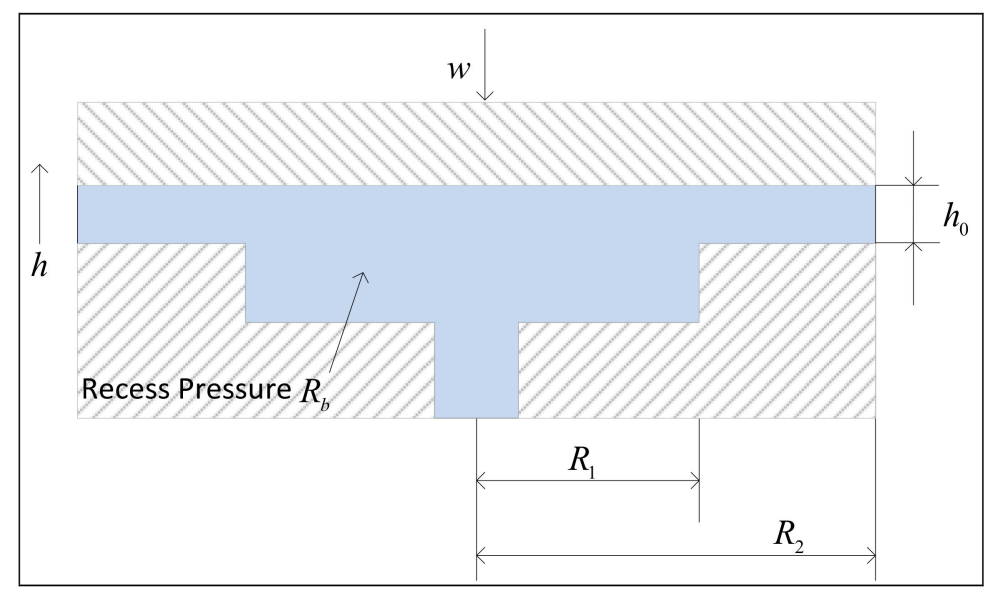

Figure 1. Hydrostatic thrust bearing.

The motion dynamics of a hydrostatic thrust bearing is given as follows:

$$
M \ddot{h}=f+w+\delta_{d}
$$

where $\delta_{d}$ is an unknown disturbance. The force of the oil film depends upon the distribution of the pressure. Let us suppose that the pressure in the recess region is constant, and the pressure of the restricted region is expressed by the Reynolds equation [24]:

$$
\frac{h^{3}}{12 \mu}\left(\frac{\partial^{2} p}{\partial r^{2}}+\frac{1}{r} \frac{\partial p}{\partial r}\right)=\dot{h}
$$

Applying the integration to Equation (2) yields the following expression:

$$
p(r)=C_{1} \ln (r)+\frac{3 \mu \dot{h} r^{2}}{\left(h+h_{0}\right)^{3}}+C_{2}
$$

Applying the boundary conditions $p\left(R_{1}\right)=P_{b}$ and $p\left(R_{2}\right)=0$ to Equation (3) yields the following:

$$
\left\{\begin{array}{l}
C_{1} \ln \left(R_{1}\right)+C_{2}=P_{b}-\frac{3 \mu \dot{h} R_{1}^{2}}{\left(h+h_{0}\right)^{3}} \\
C_{1} \ln \left(R_{2}\right)+C_{2}=0-\frac{3 \mu h R_{2}^{2}}{\left(h+h_{0}\right)^{3}}
\end{array}\right.
$$

Solving Equation (4) and substituting it in Equation (3) yields

$$
p(r)=\ln (r) \frac{P_{b}\left(h+h_{0}\right)^{3}-3 \mu \dot{h}\left(R_{1}^{2}-R_{2}^{2}\right)}{\left(h+h_{0}\right)^{3} \ln \frac{R_{1}}{R_{2}}}+\frac{3 \mu \dot{h} r^{2}}{\left(h+h_{0}\right)^{3}}-\frac{P_{b}\left(h+h_{0}\right)^{3} \ln R_{2}-3 \mu \dot{h}\left(R_{1}^{2} \ln R_{2}-R_{2}^{2} \ln R_{1}\right)}{\left(h+h_{0}\right)^{3} \ln \frac{R_{1}}{R_{2}}}
$$

Annular fluid force is expressed as follows:

$$
F_{\text {annular }}=2 \pi \int_{R 1}^{R 2} p(r) r d r
$$


The total fluid film force is given by the following relations:

$$
\left\{\begin{array}{c}
f=F_{\text {annular }}+\pi R_{1}^{2} P_{b} \\
f=\pi\left(R_{1}^{2}-R_{2}^{2}\right) \frac{3 \mu \dot{h}\left(R_{1}^{2}+R_{2}^{2}\right) \ln \frac{R_{1}}{R_{2}}-3 \mu \dot{h}\left(R_{1}^{2}-R_{2}^{2}\right)+P_{b}\left(h+h_{0}\right)^{3}}{2 \ln \frac{R_{1}}{R_{2}}\left(h+h_{0}\right)^{3}}
\end{array}\right.
$$

Let the unmodelled dynamics such as leakage, change in viscosity, fluid film friction losses, and pocket pressure losses be represented by $\delta_{m}$. The unmodelled dynamics often lowers the fluid film force, so Equation (7) is rewritten as follows:

$$
f-\delta_{m}=\pi\left(R_{1}^{2}-R_{2}^{2}\right) \frac{3 \mu \dot{h}\left(R_{1}^{2}+R_{2}^{2}\right) \ln \frac{R_{1}}{R_{2}}-3 \mu \dot{h}\left(R_{1}^{2}-R_{2}^{2}\right)+P_{b}\left(h+h_{0}\right)^{3}}{2 \ln \frac{R_{1}}{R_{2}}\left(h+h_{0}\right)^{3}}
$$

Taking viscosity as a control input, the rearrangement of Equation (8) yields the following expression:

$$
f-\delta_{m}=B P_{b}+\frac{A \dot{h}}{\left(h+h_{0}\right)^{3}} u_{1}
$$

where

$$
\begin{gathered}
A=\pi\left(R_{1}^{2}-R_{2}^{2}\right)\left[\frac{3\left(R_{1}^{2}+R_{2}^{2}\right) \ln \frac{R_{1}}{R_{2}}-3\left(R_{1}^{2}-R_{2}^{2}\right)}{2 \ln \frac{R_{1}}{R_{2}}}\right], \\
B=\frac{\pi\left(R_{1}^{2}-R_{2}^{2}\right)}{2 \ln \frac{R_{1}}{R_{2}}}
\end{gathered}
$$

Equations (1) and (9) are combined to produce a state space form, which is expressed as follows:

$$
\begin{gathered}
\dot{X}=F_{1}(x)+g_{1}(x) u_{1} \\
Y=C X
\end{gathered}
$$

where

$$
F_{1}(x)=\left[\begin{array}{ll}
\dot{h} & \left(B P_{b}+w+\delta_{m}+\delta_{d}\right) / M
\end{array}\right]^{T}, g_{1}(x)=\left[\begin{array}{ll}
0 & \frac{A \dot{h}}{M\left(h+h_{0}\right)^{3}}
\end{array}\right]^{T}, C=\left[\begin{array}{ll}
1 & 0
\end{array}\right]^{T}
$$

\subsection{Active Supply Pressure as Control Input}

In Model 2, supply pressure is taken as a control input. The capillary-controlled hydrostatic thrust bearing, which is pressurized by an external active pressure supply, is shown in Figure 2.

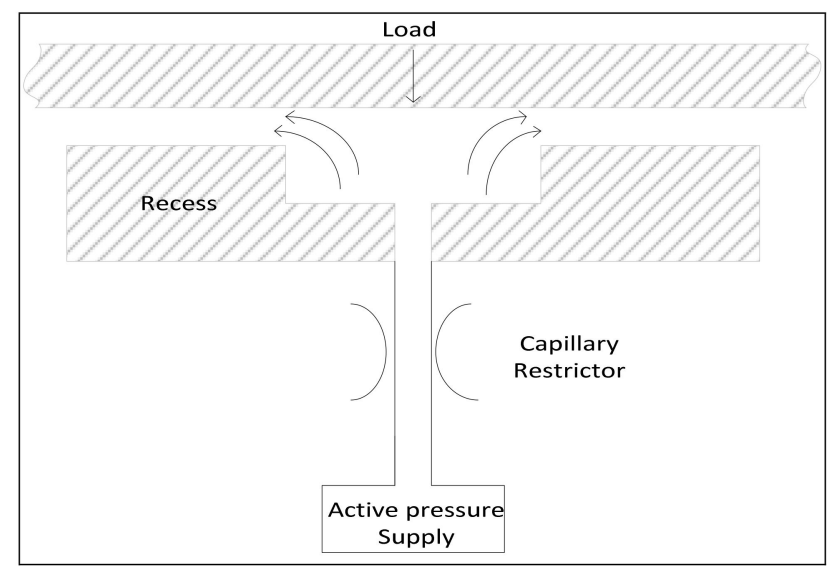

Figure 2. Thrust bearing having active supply pressure. 
The rate of flows for the input and output sections are expressed as follows:

$$
\left\{\begin{array}{c}
Q_{\text {in }}=\frac{\pi d^{4}\left(P_{S}-P_{b}\right)}{128 \mu L} \\
Q_{\text {out }}=-\frac{\pi R_{2} h^{3}}{6 \mu} \frac{\partial p}{\partial r} r=R_{2}
\end{array}\right.
$$

The continuity equation is given by the following expression:

$$
Q_{\text {in }}=Q_{\text {out }}+\pi R_{2}^{2} \dot{h}
$$

By substituting the pressure distribution into Equation (12), one obtains the following relation:

$$
\frac{\pi d^{4}\left(P_{s}-P_{b}\right)}{128 \mu L}+\frac{\pi P_{b}\left(h+h_{0}\right)^{3}-3 \pi \dot{h} \mu\left(R_{1}^{2}-R_{2}^{2}\right)}{6 \mu \ln \frac{R_{1}}{R_{2}}}=0
$$

By combining Equation (13) with Equations (1) and (9), the following state space form is derived:

$$
\begin{gathered}
\dot{X}=F_{2}(x)+g_{2}(x) u_{2} \\
Y=C X
\end{gathered}
$$

where

$$
\begin{gathered}
F_{2}(x)=\frac{192\left(-\frac{2}{3}\left(w+\delta_{m}+\delta_{d}\right)\left(h+h_{0}\right)^{3}+\pi \mu \dot{h}\left(R_{1}^{4}-R_{2}^{4}\right)\right)\left(L\left(h+h_{0}\right)^{3}-\frac{3 d^{4}}{64} \ln \frac{R_{1}}{R_{2}}\right)+9 \pi \mu \dot{h} d^{4}\left(R_{1}-R_{2}\right)^{2}\left(R_{1}+R_{2}\right)^{2}}{128 M\left(h+h_{0}\right)^{3}\left(L\left(h+h_{0}\right)^{3}-\frac{3 d^{4}}{64} \ln \frac{R_{1}}{R_{2}}\right)} \\
g_{2}(x)=-\frac{3 \pi d^{4}\left(R_{1}^{2}-R_{2}^{2}\right)}{128 M\left(L\left(h+h_{0}\right)^{3}-\frac{3 d^{4}}{64} \ln \frac{R_{1}}{R_{2}}\right)}, C=\left[\begin{array}{ll}
1 & 0
\end{array}\right]^{T}
\end{gathered}
$$

\subsection{Membrane-Controlled Thrust Bearing}

In this model, an active membrane restrictor is introduced for controlling recess pressure. The schematic for the membrane-compensated hydrostatic thrust bearing is shown in Figure 3.

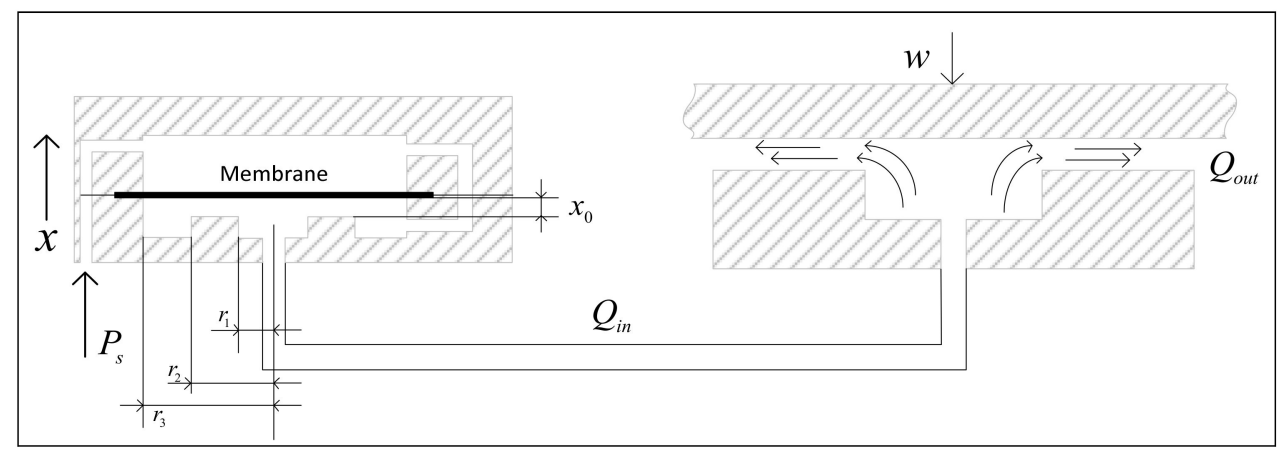

Figure 3. Schematic for membrane-compensated hydrostatic bearing.

The flow into the hydrostatic bearing is given by the following expression [24]:

$$
\begin{gathered}
Q_{\text {in }}=\left.\frac{\pi r\left(x+x_{0}\right)^{3}}{6 \mu} \frac{\partial p_{m e m}}{\partial r}\right|_{r=r_{2}}-\pi r_{2}^{2} \dot{x} \\
Q_{\text {out }}=-\left.\frac{\pi R_{2} h^{3}}{6 \mu} \frac{\partial p}{\partial r}\right|_{r}=R_{2}
\end{gathered}
$$


The continuity equation for the hydrostatic thrust bearing is expressed as follows:

$$
Q_{\text {in }}=Q_{o u t}+\pi R_{2}^{2} \dot{h}
$$

$P_{b}$ is obtained by substituting the pressure distribution into Equations (15)-(17).

$$
P_{b}=-\frac{\pi R_{2}\left(h+h_{0}\right)^{3}}{6 \mu}\left(\frac{6 \mu \dot{h} R_{2}}{\left(h+h_{0}\right)^{3}}-\frac{3 \mu \dot{h}\left(R_{1}^{2}-R_{2}^{2}\right)}{R_{2}\left(h+h_{0}\right)^{3}\left(\ln R_{1}-\ln R_{2}\right)}\right)+\pi R_{2}^{2} \dot{h}+\pi r_{2}^{2} \dot{x}+\frac{\frac{P_{s}\left(x+x_{0}\right)^{3}+3 \mu \dot{x}\left(r_{1}^{2}-r_{2}^{2}\right)}{\left(\ln r_{1}-\ln r_{2}\right)}-6 \mu r_{2}^{2} \dot{x}}{\frac{\left(x+x_{0}\right)^{3}}{\left(\ln r_{1}-\ln r_{2}\right)}+\frac{\left(h+h_{0}\right)^{3}}{\left(\ln R_{1}-\ln R_{2}\right)}}
$$

By combining Equation (18) with Equations (1) and (9), the state space form of the membrane-restrictor-controlled hydrostatic bearing is formulated. The state space form of the membrane-restrictor-controlled hydrostatic bearing is given by the following expressions:

$$
\begin{gathered}
\dot{X}=F_{3}(x)+g_{3}(x) u_{3} \\
Y=C X
\end{gathered}
$$

where

$$
\begin{gathered}
F_{3}(x)=\left[\frac{A \mu}{M\left(h+h_{0}\right)^{3}}+\frac{B \pi\left(R_{1}^{2}-R_{2}^{2}\right)}{2 M\left(\ln R_{1}-\ln R_{2}\right)}\right] \dot{h}+\frac{B P_{s}\left(x+x_{0}\right)^{3}}{M\left(\ln _{1}-\ln r_{2}\right)\left[\frac{\left(x+x_{0}\right)^{3}}{\left(\ln r_{1}-\ln _{2}\right)}+\frac{\left(h+h_{0}\right)^{3}}{\left(\ln R_{1}-\ln R_{2}\right)}\right]}+\frac{B w}{M} \\
g_{3}(x)=\frac{B \pi r_{2}^{2}}{M}+\frac{3 \mu B\left(r_{1}^{2}-r_{2}^{2}\right)-6 \mu r_{2}^{2} B\left(\ln _{1}-\operatorname{lnr}_{2}\right)}{M\left(\operatorname{lnr}_{1}-\ln r_{2}\right)\left[\frac{\left(x+x_{0}\right)^{3}}{\left(\ln r_{1}-\ln r_{2}\right)}+\frac{\left(h+h_{0}\right)^{3}}{\left(\ln R_{1}-\ln R_{2}\right)}\right]}
\end{gathered}
$$

Equation (19) shows a complete mathematical model of the hydrostatic thrust bearing with membrane restrictor.

From Equations (10), (14) and (19), the terms $F_{1}(x), F_{2}(x)$ and $F_{3}(x)$ are unknown. In previously published work [23], $F_{1}(x), F_{2}(x)$, and $F_{3}(x)$ were used in the design of the controller. Practically speaking, it is not easy to calculate $F_{1}(x), F_{2}(x)$, and $F_{3}(x)$. Thus in the current research work, this limitation is addressed using an extended state observer. In our proposed method, the controller is formulated based on the estimation of $F_{1}(x)$, $F_{2}(x)$, and $F_{3}(x)$.

\section{LESO-Based Controller Design}

Theorem 1. Lyapunov's stability theorem.

Let us suppose a time variable function $x=f(x, t)$, where its equilibrium point is at its origin. Additionally, assume that $V$ is a continuous differentiable function, such that the following relation is true:

$$
\left\{\begin{array}{c}
\gamma_{1}(\|x\|) \leq V(x, t) \leq \gamma_{2}(\|x\|) \\
\frac{d V}{d t}=\frac{\partial V}{\partial t}+\frac{\partial V}{\partial x} f(x, t) \leq \gamma_{3}(\|x\|)
\end{array}\right.
$$

where $\gamma_{1}, \gamma_{2}, \gamma_{3}$ are functions having class $K$, which exists for $\forall t \geq 0$, and $x$ is uniformly and asymptotically stable.

Theorem 2. Convergence and Boundedness.

Let us suppose $D=\{x \in R \mid x<r\}$, and $x=f(x, t)$ is locally Lipchitz for $D \times[0, \infty)$. Suppose that $V$ belongs to a class that is continuous and differentiable. Then

$$
\left\{\begin{array}{c}
\gamma_{1}(\|x\|) \leq V(x, t) \leq \gamma_{2}(\|x\|) \\
\frac{d V}{d t}=\frac{\partial V}{\partial t}+\frac{\partial V}{\partial x} f(x, t) \leq-W(x) \leq 0
\end{array}\right.
$$


For $\forall t \geq 0, \forall x \in D$, where $\gamma_{1}$ and $\gamma_{2}$ are class $K$ functions and have defined intervals $(0, r), W(x)$ is continuous at $D$, while $\dot{V}$ is continuous at $t$. All solutions to $x=f(x, t)$, with $x\left(t_{0}\right)<\gamma_{2}^{-1}\left(\gamma_{1}(r)\right)$, are bound and satisfy

$$
W(x(t)) \rightarrow 0 \text { as } t \rightarrow \infty
$$

Let us suppose $h, \dot{h}=x_{1}, x_{2}$, Then, the proposed models can be described by state space as follows:

$$
\psi=\left\{\begin{array}{c}
\dot{x}_{1}=x_{2} \\
\dot{x}_{2}=f(x)+g(x) u \\
y=x_{1}
\end{array}\right.
$$

Let us suppose the extended state is $x_{3}=f(x)$. Then

$$
\bar{\psi}=\left\{\begin{array}{c}
\dot{x}_{1}=x_{2} \\
\dot{x}_{2}=x_{3}+g(x) u \\
\dot{x}_{3}=q \\
y=x_{1}
\end{array}\right.
$$

We rewrite the extended order system by defining the extended state vector as follows: $X=\left[x_{1}, x_{2}, x_{3}\right]^{T} ;$

$$
\left\{\begin{array}{c}
\dot{X}=\bar{A} X+\bar{B} u+\bar{E} q \\
Y=\bar{C}_{1} X_{1}
\end{array}\right.
$$

where

$$
\bar{A}=\left[\begin{array}{lll}
0 & 1 & 0 \\
0 & 0 & 1 \\
0 & 0 & 0
\end{array}\right], \bar{B}=\left[\begin{array}{c}
0 \\
g(x) \\
0
\end{array}\right], \bar{C}_{1}=\left[\begin{array}{l}
1 \\
0 \\
0
\end{array}\right]^{T}, \bar{E}=\left[\begin{array}{l}
0 \\
0 \\
1
\end{array}\right]
$$

Now the extended state observer can be designed as follows:

$$
\dot{\hat{X}}=\bar{A} \hat{X}+\bar{B} u+L \bar{C}(X-\hat{X})
$$

Equation (26) represents the extended state observer. The extended state observer is proposed when it is difficult to access all the states of the system [24-28]. There are several methods to find observer gains. One typical example is [28].

$$
L=\left[l_{1}, l_{2}, l_{3}\right]=\left[4 \omega, 6 \omega^{2}, 4 \omega^{3}\right]
$$

New state variables based on the controller are defined as follows:

$$
\begin{gathered}
\hat{z}_{1}=\hat{x}_{1}-x_{d} \\
\hat{z}_{2}=\hat{x}_{2}-\alpha_{1}\left(\hat{z}_{1}\right) \\
\hat{z}_{3}=\hat{x}_{3}-\alpha_{2}\left(\hat{z}_{1}, \hat{z}_{2}\right)
\end{gathered}
$$

where $x_{d}$ is the desired input, and virtual control inputs are represented as $\alpha_{1}\left(\hat{z}_{1}\right)$ and $\alpha_{2}\left(\hat{z}_{1}, \hat{z}_{2}\right)$. It (the virtual controllers) helps to attain convergence as well as stability, with the help of Theorems (1) and (2).

Remark 1. In order to achieve stability, state errors must converge to zero. The state errors are defined by Equations (28)-(30). 
Step 1:

In order to prove the convergence and stability of the system presented in Equation (28), a positive semidefinite Lyapunov function is given by the following relationship:

$$
V_{1}=\frac{1}{2} \hat{z}_{1}^{2}
$$

The derivative of $z_{1}$ yields the following expression:

$$
\dot{z}_{1}=\hat{z}_{2}+\alpha_{1}\left(\hat{z}_{1}\right)-\dot{x}_{d}
$$

That guarantees stability if the following expression is valid

$$
\alpha_{1}\left(\hat{z}_{1}\right)=-k_{1} \hat{z}_{1}+\dot{x}_{d}
$$

then

$$
\dot{V}_{1}=\hat{z}_{1} \hat{z}_{2}-k_{1} \hat{z}_{1}^{2}
$$

Step 2:

One can define a positive definite Lyapunov function for convergence and stability, as shown in Equation (29).

$$
V_{2}=V_{1}+\frac{1}{2} \hat{z}_{2}^{2}
$$

That guarantees stability if the control law is chosen as follows:

$$
u=\frac{1}{g(x)}\left[\dot{\alpha}_{1}\left(\hat{z}_{1}\right)-\hat{z}_{1}-\hat{x}_{3}-k_{2} \hat{z}_{2}\right]
$$

Then it is easy to show that

$$
\dot{V}_{2}=-k_{1} \hat{z}_{1}^{2}-k_{2} \hat{z}_{2}^{2}
$$

\subsection{Multiobjective Performance Criteria}

The multiobjective optimization for tuning the controller's parameters has been popular in recent decades [29-31]. Several criteria are used to tune the parameters of controllers. Three commonly used performance criteria are integral of squared error (ISE), absolute error (IAE), and time-weighted absolute error (ITAE). The current research will use multiobjective performance criteria. These criteria will use performance variables such as overshoot, settling time, rise time, and tracking convergence error. Performance variables are calculated online by simulating the model. The objective function is updated with new values of performance variables after each simulation. The multiobjective performance criteria are given by

$$
f(k)=q_{1}\left[\sum_{0}^{t}\left(h_{r}-h\right)^{2}\right]+q_{2}\left[\left|T_{S}\right|\right]+q_{3}\left[\left|T_{r}\right|\right]+q_{4}\left[\left|O_{S}\right|\right]
$$

where $q_{1}, q_{2}, q_{3}$, and $q_{4}$ are weighting factors. The increase in value of the weighting factor for specific terms results in the improved performance of that term at the expense of degradation in performance for other terms. $T_{r}$ is the rise time, $O_{s}$ is the percentage overshoot, $h_{r}$ is the reference fluid film thickness and $T_{s}$ is the settling time.

\subsection{Particle Swarm Optimization (PSO)}

Particle swarm optimization is the best algorithm to tune the parameters of control techniques [29,32-34]. Particle swarm optimization is optimizing the multiobjective function against the different values of the tuning parameters. The multiobjective performance criteria consist of rise time, settling time, percentage overshoot, and error signal. In other words, it can be said that PSO optimizes rise time, settling time, percentage overshoot, 
and error. A set of 3-dimensional tuning parameters $\left[\omega, K_{1}, K_{2}\right]$ is used for the extendedobserver-based controller. The value of this vector is found by using PSO. Some important terms for PSO are as follows:

1. $\Theta=\left[\theta_{1}, \theta_{2}, \theta_{3}\right]=\left[\omega, K_{1}, K_{2}\right]$. It gives the value of the tuning parameters. For the $n$th iteration, the $i$ th particle is represented by $\Theta_{i}(n)=\left[\theta_{i, 1}(n), \theta_{i, 2}(n), \theta_{i, 3}(n)\right]$. The upper and lower bound $\left[\theta_{\min }, \theta_{\max }\right]$ are defined for the optimizing parameters.

$$
\theta_{j}=\left\{\begin{array}{cc}
\theta_{\min } & \text { if } \theta_{j}<\theta_{\min } \\
\theta_{j} & \text { if } \theta_{\min } \leq \theta_{j} \leq \theta_{\max } \\
\theta_{\max } & \text { if } \theta_{j}>\theta_{\max }
\end{array}\right.
$$

2. Velocity $V(n)$ : it represents the velocity of particle $\Theta(n)$. For the $n$th iteration, the $i$ th particle velocity is given by

$$
V_{i}(n)=\left[v_{i, 1}(n), v_{i, 2}(n), v_{i, 3}(n)\right]
$$

3. Individual best $P(n)$ : the cost function value of the particle is compared with the best cost function value. The particle that has the best cost function value is known as the individual best. The individual best is obtained when the $i$ th particle holds the following condition:

$$
J\left(P_{i}(n)\right) \leq J\left(\Theta_{i}(\tau)\right) \quad \therefore \tau \leq n
$$

where $J\left(P_{i}\right)$ and $J\left(\Theta_{i}\right)$ are the cost function for $P_{i}$ and $\Theta_{i}$. The $i$ th individual best for the $n$th iteration is given by

$$
P_{i}(n)=\left[p_{i, 1}(n), p_{i, 2}(n), p_{i, 3}(n)\right]
$$

4. Global best $G(n)$ : It is the best outcome among all the individual best values. For the $n$th iteration, the global best $G(n)=\left[g_{1}(n), g_{2}(n), g_{3}(n)\right]$ is found when the condition of Equation (43) is satisfied

$$
J(G(n)) \leq J\left(P_{i}(n)\right) \quad \therefore i=1,2, \ldots, H
$$

5. Position and velocity are updated with respect to individual best and global best position. The $i$ th particle's position and velocity is given by

$$
\begin{array}{cc}
v_{i, j}(n+1)=w v_{i, j}(n)+c_{1} r_{1}\left(p_{i, j}(n)-\theta_{i, j}(n)\right)+c_{2} r_{2}\left(g_{j}(n)-\theta_{i, j}(n)\right) & \therefore i=1,2,3 \ldots, H \\
\theta_{i, j}(n+1)=\theta_{i, j}(n)+v_{i, j}(n+1) & \therefore j=1,2,3, . .
\end{array}
$$

where $r_{1}$ and $r_{2}$ represent random numbers, $w$ is an inertial weight, $c_{1}$ as well as $c_{2}$ are positive acceleration constants, $v_{i, j}(n)$ and $v_{i, j}(n+1)$ are the current and the next velocity, respectively.

6. Termination condition: Termination criteria are often two types. The first is the required number of iterations that have been achieved, while the second is the desired value of the objective function. The current research will try to achieve the "required number of iterations".

A particle swarm optimization algorithm (PSO) is used to tune the parameters of the controller. The controller is given by Equation (36). The design steps to tune the parameters of the controller are given by

Step 1: Define a multiobjective function. The simulation is performed online, and variables such as error, settling time, overshoot, and rise time are updated to Equation (38) to find the multiobjective function. The total number iterations and parameters $w, c_{1}$, $c_{2}$ are defined.

Step 2: Stop PSO if the required number of iterations have been reached, or else update the multiobjective function by simulating the model and updating the monitoring variables. Step 3: Update the position of individual best according to Equation (41).

Step 4: Update the position of global best according to Equation (43). 
Step 5: Update position and velocity according to Equation (44). Apply lower and upper boundaries by using Equation (39) if the value goes beyond the desired interval. Step 6: go to Step 2.

The controller presented in Equation (36) has an inherent advantage of requiring a position tracking signal of the system; it does not require any other state variables. Previously published literature [23] has used factor $F(x)$ in the controller design process. It is almost impossible to find $F(x)$ in practical applications. The current proposed controller eliminates the requirement for finding the unknown term $F(x)$. The control system presented by Equation (36) can be used by the models of Equations (10), (14), and (19).

\section{Results}

To check the effectiveness of the proposed method, simulations were done in Matlab/Simulink. Some procedures and calculations were done before performing the simulations. It included the external load and assuming initial values of $h_{0}, x_{0}, \dot{h}, \ddot{h}, \dot{x}, \ddot{x}$, and $P_{s}$. Simulations were performed using the Simulink parameters given in Sha et al. [23].

In Model 1, control input is fluid viscosity. The control law of Equation (36) is valid only for the model of Equation (10) if the initial velocity is not zero. If the initial velocity is zero, then the control input would achieve an infinity value. To avoid such circumstances, the initial velocity is kept at nonzero. The control law of Equation (36) is implemented for the system model of Equation (10). The external load is $w=1500 \mathrm{~N}$, and the supply pressure is $P_{S}=1 \mathrm{Mpa}$. The obtained results were compared with previously published literature [23]. Figure 4 shows the time displacement plot. From the presented results, it is confirmed that the proposed mathematical model has faster tracking performance in achieving the desired fluid film thickness. The rise time $T_{\mathrm{r} 1}$ and settling time $\mathrm{T}_{\mathrm{s} 1}$ for the present study are measured as 2.01 and $3.64 \mathrm{~s}$, respectively, while with the method presented in [23], the following measurements are recorded: $\mathrm{T}_{\mathrm{r} 2}=3.90 \mathrm{~s}$ and $\mathrm{T}_{\mathrm{s} 2}=6.07 \mathrm{~s}$ The comparison of the rise time and the settling time shows that the proposed model has a faster tracking response to achieve the desired displacement $h$.

In Model 2, supply pressure is taken as a control input while output is fluid film thickness. The external load is kept at $w=1000 \mathrm{~N}$. Two types of controller, such as the sliding mode controller (Sha et al. [23]) and the observer-based back-ping controller, are applied to the proposed model. The result (Figure 5) shows that the proposed model has a faster response (less rise time and settling time) under the observer-based backstepping controller compared to sliding mode control (from the published literature [23]). It can be seen from Figure 5 that the proposed controller has better performance in terms of higher initial supply pressure and faster tracking performance to achieve the required fluid film thickness. Furthermore, the rise time $\mathrm{T}_{\mathrm{r} 1}$ and settling time $\mathrm{T}_{\mathrm{s} 1}$ under observer-based backstepping control (present study) are measured as 0.13 and $0.23 \mathrm{~s}$, respectively, while it is 0.54 and $0.97 \mathrm{~s}$ for the method proposed in [23]. A comparison with respect to rise time and settling time shows that the proposed method tracks faster to achieve the desired displacement or fluid film thickness.

In Model 3, a hydrostatic thrust bearing, controlled by a membrane restrictor, is proposed. The thickness of the fluid film is taken as an output. The simulations were performed for the proposed method and previous work [23]. It can be seen from Figure 6 that the proposed scheme shows better performance in terms of convergence and rise and settling times compared to previous work. Supply pressure and fluid viscosity are also changed to further verify the effectiveness of the membrane-restrictor-controlled thrust bearing under observer-based backstepping control. The external supply pressure is changed from 1 to $7 \mathrm{Mpa}$. By changing the external supply pressure, there is an improvement in tracking performance with the proposed method. The rise time and settling time are measured as 0.037 and $0.074 \mathrm{~s}$, respectively, under $1 \mathrm{Mpa}$ and 0.016 and $0.026 \mathrm{~s}$ under $7 \mathrm{Mpa}$. Figure 7a,b shows the simulation results with the proposed method and reference [23], respectively. Normally, in practical systems, there is an improvement in the tracking performance of hydrostatic thrust bearings by increasing external supply pressure, while the method 
presented in [23] showed no such improvements. Hence, the results obtained with the proposed method are more practical under varying conditions of supply pressure.

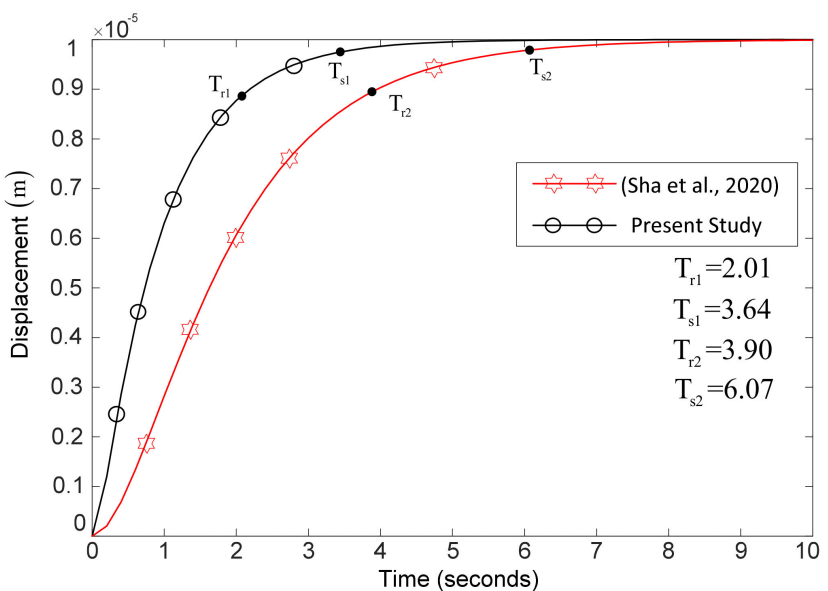

(a)

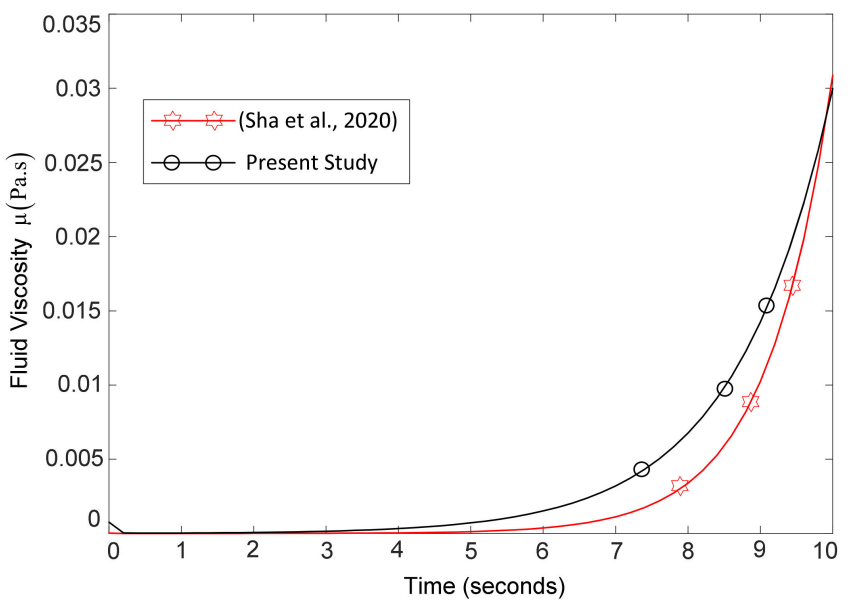

(b)

Figure 4. Control input (viscosity) and tracking performance. (a) Tracking performance to attain a desired fluid film thickness. (b) Fluid viscosity as a control input.

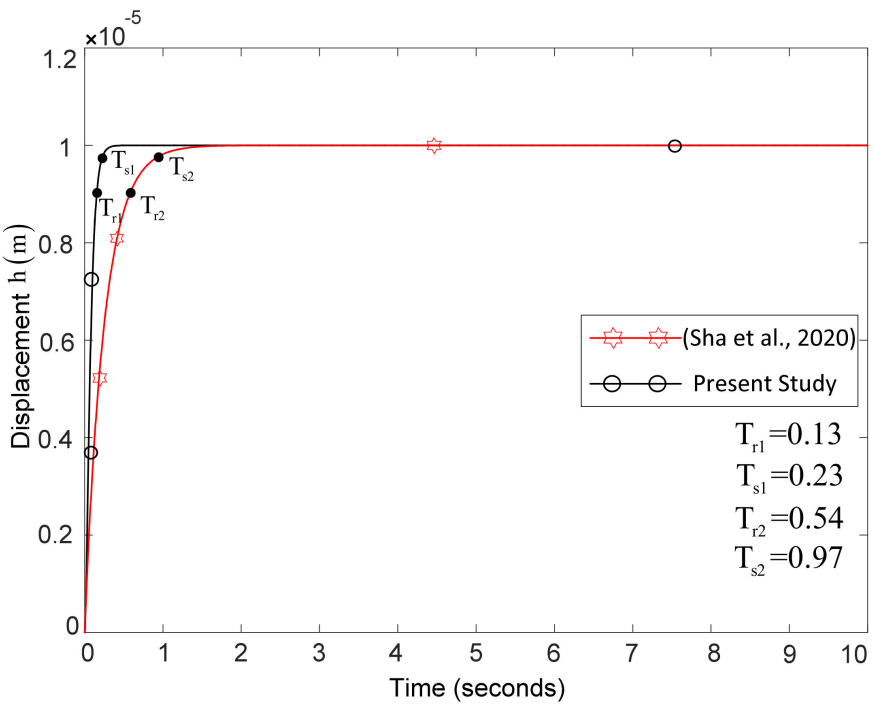

(a)

Figure 5. Cont. 


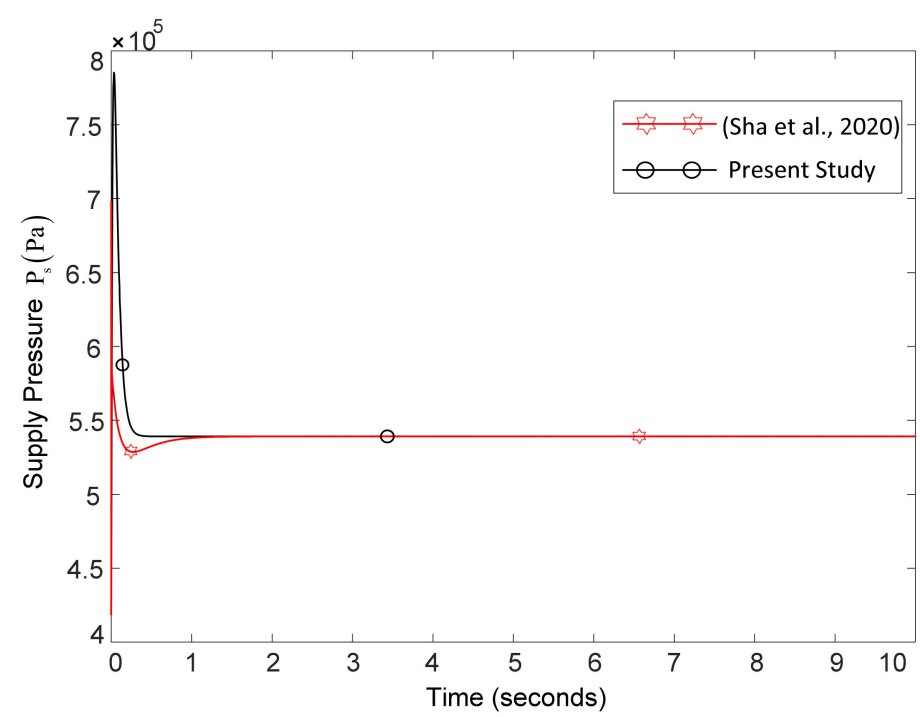

(b)

Figure 5. Control input (supply pressure) and tracking performance. (a) Tracking performance to attain desired fluid film thickness. (b) Supply pressure as a control input.

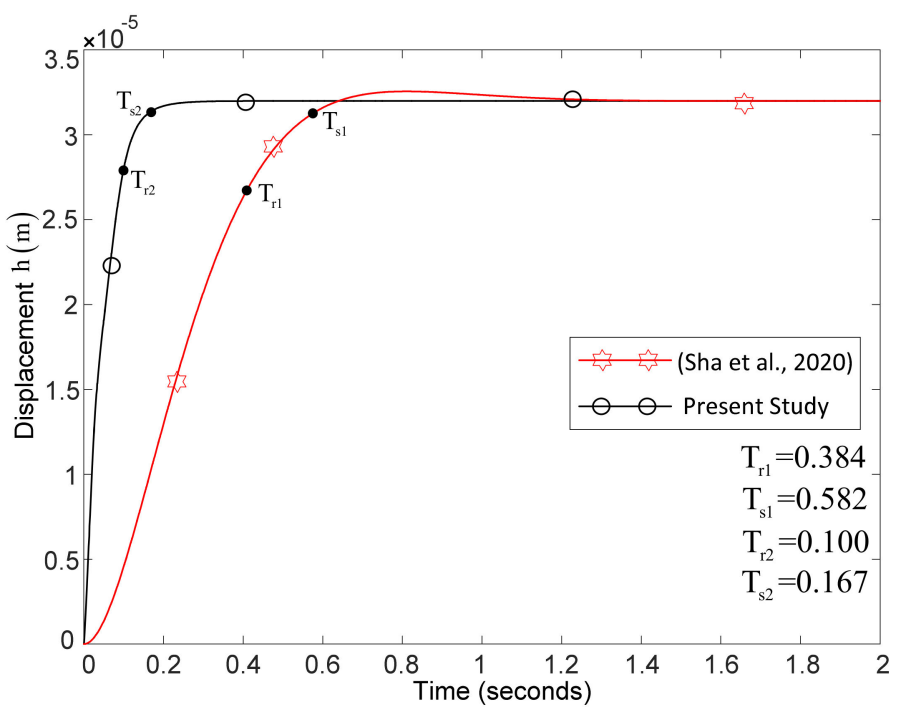

Figure 6. Comparison of tracking performance.

Similar behavior has been noted by changing viscosity. Figure 8 shows the effect of viscosity on tracking performance. It is found that with the proposed method and by increasing viscosity, the system response is slower to achieve the desired fluid film thickness, while it had no significant effect on the performance of the system with the method proposed in [23]. The proposed method is more practical.

One of the most important factors for performance evaluation of a hydrostatic thrust bearing is its ability to reject the effect of the external load that acts on it during the operation of machines. A square wave load of magnitude $4500 \mathrm{~N}$ and pulse width $50 \%$ is applied (Figure 9). The amplified diagram for load rejection performance is shown in Figure 9. The load rejection performance of the system with the proposed method and the previously reported method [23] is compared in Figure 9. The result shows that the present study has less change in film thickness $\left(\Delta h_{2}=3.6 \mu \mathrm{m}\right)$ compared to the published literature $\left(\Delta h_{1}=6.8 \mu \mathrm{m}\right)$. It shows that the proposed method has better load rejection performance compared to the previously published method of [23]. 


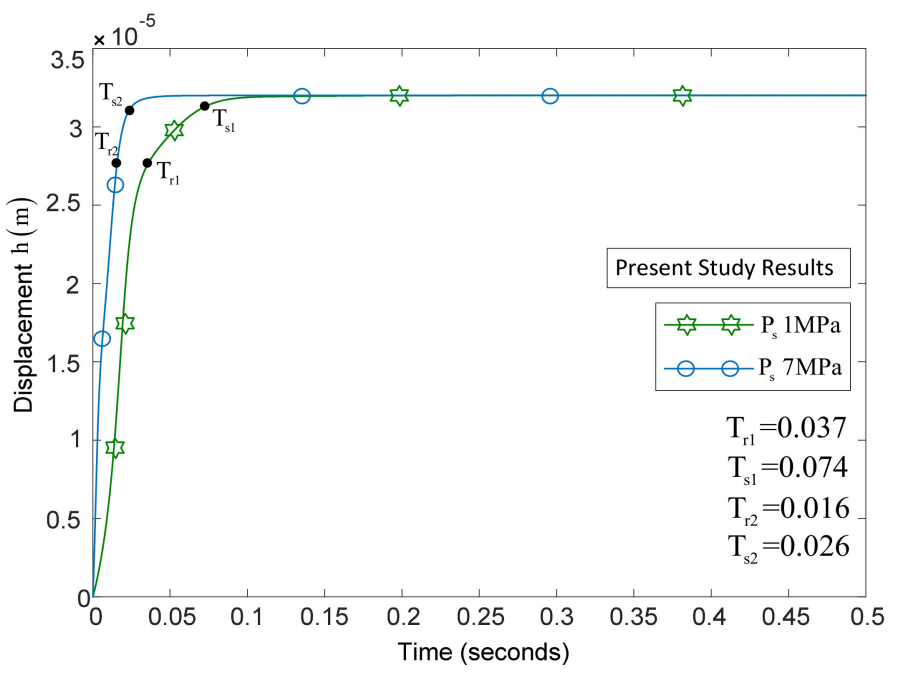

(a)

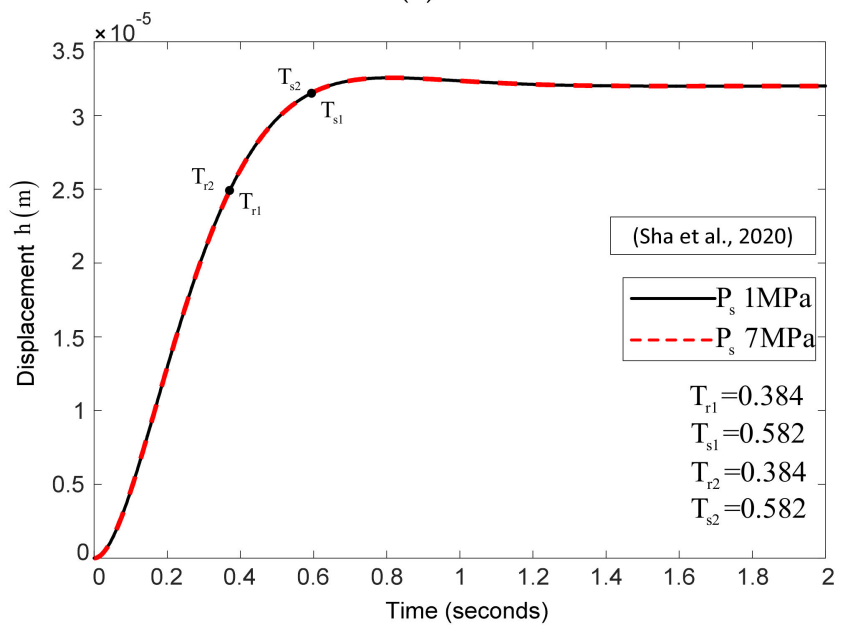

(b)

Figure 7. Tracking performance under different supply pressure. (a) Present study. (b) Literature research work.

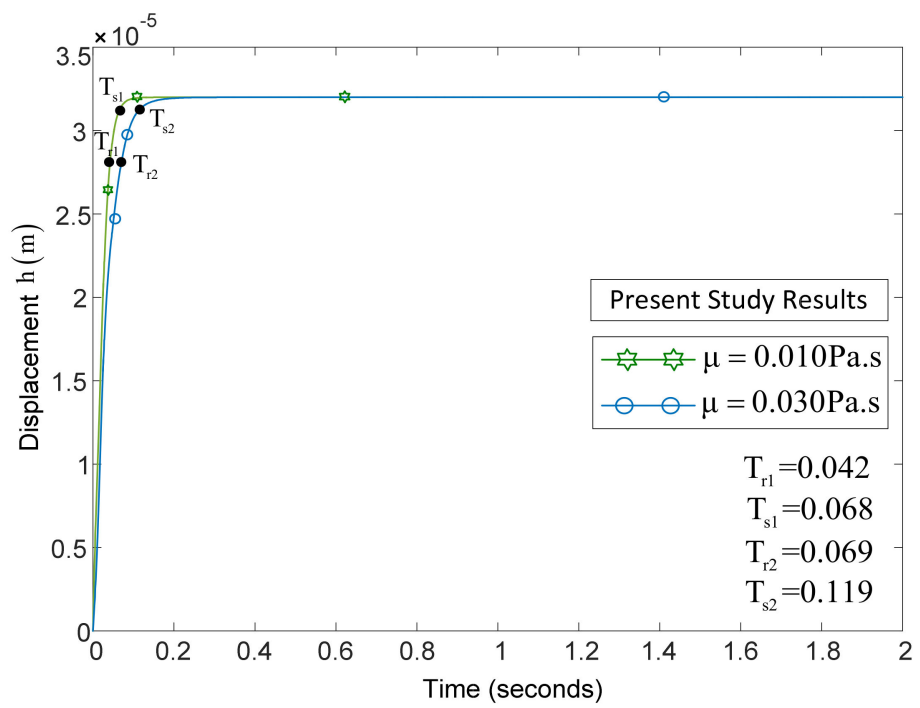

(a)

Figure 8. Cont. 


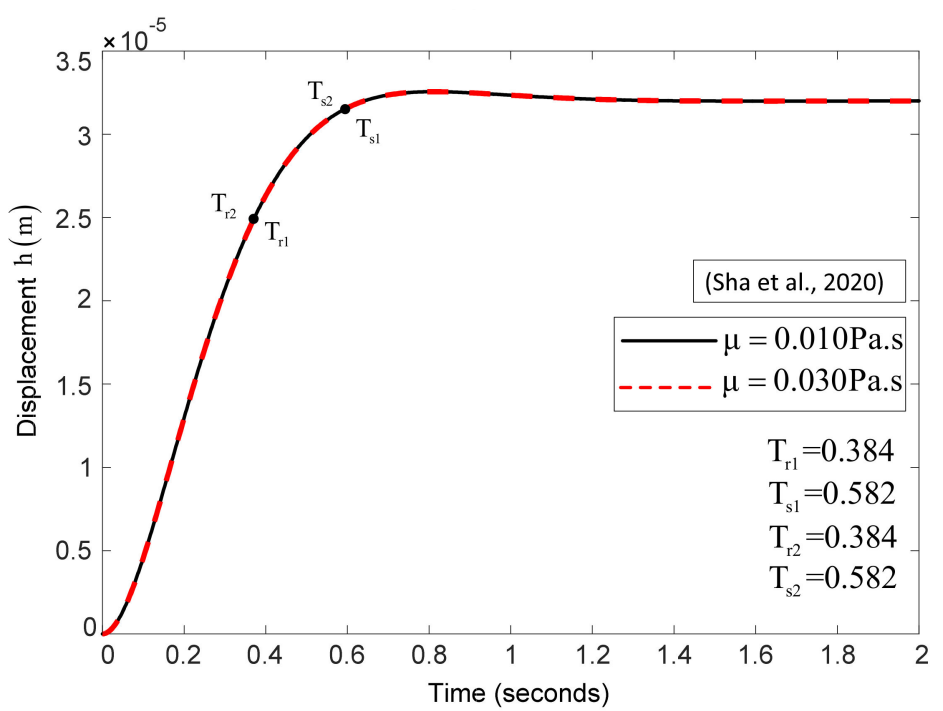

(b)

Figure 8. Tracking performance under different viscosity. (a) Present study. (b) Literature research work.

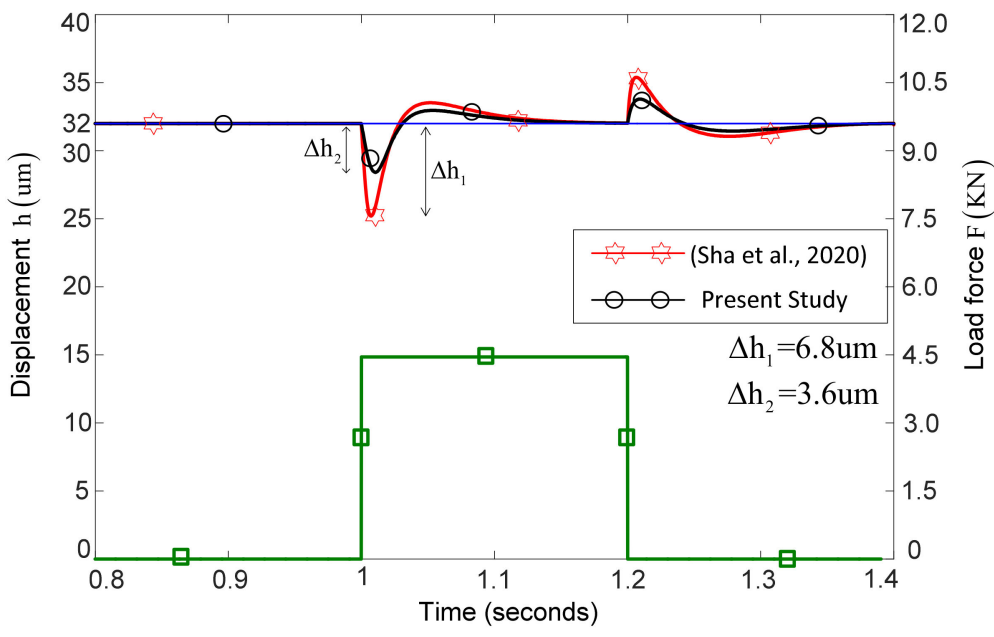

Figure 9. Load rejection performance.

\section{Conclusions}

This research presents a backstepping combined extended-observer-based active lubrication method to improve the performance of thrust bearings. The current research presents a sensorless nonlinear control method that offers advantages over the published literature in terms of handling unmodeled dynamics, unavailable motion states, nonlinearities, and unknown disturbance. Moreover, the proposed method utilizes fewer sensors compared to a previously reported method [23]. The parameters of the proposed method are tuned using the multiobjective particle swarm optimization method. From the presented results, it is concluded that the system achieves better performance in terms of convergence, rising, and settling times under the action of the proposed control scheme.

Author Contributions: Conceptualization, W.U.R. and W.K.; methodology, N.U.; software, W.U.R.; validation, W.U.R., W.K. and M.D.S.C.; formal analysis, K.T.; investigation, M.H.; writing-original draft preparation, W.U.R.; writing-review and editing, N.U.; funding acquisition, K.T. All authors have read and agreed to the published version of the manuscript.

Funding: This work was supported by Taif University researchers supporting project number TURSP2020/144, Taif University, Taif, Saudi Arabia. This research was also supported by grant number ENV6402012N from Prince of Songkla University. 
Institutional Review Board Statement: Not applicable.

Informed Consent Statement: Not applicable.

Data Availability Statement: Not applicable.

Acknowledgments: Authors acknowledge the support of Taif University researchers supporting project number TURSP-2020/144, Taif University, Taif, Saudi Arabia. Authors also acknowledge the financial support provided under grant number ENV6402012N from Prince of Songkla University.

Conflicts of Interest: The authors declare no conflict of interest.

\section{Nomenclature}

$\begin{array}{ll}\delta_{d} & \text { Unknown disturbance } \\ h & \text { Fluid film thickness } \\ h_{0} & \text { Initial fluid film thickness } \\ P_{S} & \text { Supply pressure } \\ \mu & \text { Fluid viscosity } \\ R_{1}, R_{2} & \text { Inner and outer radius for bearing } \\ r_{1}, r_{2}, r_{3} & \text { Radius for membrane restrictor } \\ P_{b} & \text { Recess pressure } \\ \delta_{m} & \text { Unmodelled dynamic } \\ M & \text { Mass of bearing }\end{array}$

\section{References}

1. Dadouche, A.; Conlon, M.J. Operational performance of textured journal bearings lubricated with a contaminated fluid. Tribol. Int. 2016, 93, 377-389. [CrossRef]

2. Vlădescu, S.-C.; Medina, S.; Olver, A.V.; Pegg, I.G.; Reddyhoff, T. Lubricant film thickness and friction force measurements in a laser surface textured reciprocating line contact simulating the piston ring-liner pairing. Tribol. Int. 2016, 98, 317-329. [CrossRef]

3. Tala-Ighil, N.; Fillon, M. A numerical investigation of both thermal and texturing surface effects on the journal bearings static characteristics. Tribol. Int. 2015, 90, 228-239. [CrossRef]

4. Hesselbach, J.; Abel-Keilhack, C. Active hydrostatic bearing with magnetorheological fluid. J. Appl. Phys. 2003, 93, 8441-8443. [CrossRef]

5. Wang, X.; Li, H.; Li, M.; Bai, H.; Meng, G.; Zhang, H. Dynamic characteristics of magnetorheological fluid lubricated journal bearing and its application to rotor vibration control. J. Vibroeng. 2015, 17, 1912-1928.

6. Zhang, S.; Long, Z.; Yang, X. Lubrication performance of magnetorheological fluid-lubricated rubber stern bearing test ring. J. Braz. Soc. Mech. Sci. Eng. 2021, 43, 1-10. [CrossRef]

7. Kumar, V.; Sharma Satish, C. Magneto-hydrostatic lubrication of thrust bearings considering different configurations of recess. Ind. Lubr. Tribol. 2019, 71, 915-923. [CrossRef]

8. Morosi, S.; Santos, I.F. Active lubrication applied to radial gas journal bearings. Part 1: Modeling. Tribol. Int. 2011, 44, 1949-1958. [CrossRef]

9. Pierart, F.G.; Santos, I.F. Active lubrication applied to radial gas journal bearings. Part 2: Modelling improvement and experimental validation. Tribol. Int. 2016, 96, 237-246. [CrossRef]

10. Mizumoto, H.; Arii, S.; Kami, Y.; Goto, K.; Yamamoto, T.; Kawamoto, M. Active inherent restrictor for air-bearing spindles. Precis. Eng. 1996, 19, 141-147. [CrossRef]

11. Rehman, W.U.; Luo, Y.; Wang, Y.; Jiang, G.; Iqbal, N.; Rehman, S.U.; Bibi, S. Fuzzy logic-based intelligent control for hydrostatic journal bearing. Meas. Control. 2019, 52, 229-243. [CrossRef]

12. Rehman, W.U.; Wang, X.; Cheng, Y.; Chen, Y.; Shahzad, H.; Chai, H.; Abbas, K.; Ullah, Z.; Kanwal, M. Model-based design approach to improve performance characteristics of hydrostatic bearing using multivariable optimization. Mathematics 2021, 9, 388. [CrossRef]

13. Rehman, W.U.; Wang, X.; Chen, Y.; Yang, X.; Ullah, Z.; Cheng, Y.; Kanwal, M. An active control for hydrostatic journal bearing using optimization algorithms. Ind. Lubr. Tribol. 2021, 73, 316-324. [CrossRef]

14. Rehman, W.U.; Jiang, G.; Luo, Y.; Wang, Y.; Khan, W.; Rehman, S.U.; Iqbal, N. Control of active lubrication for hydrostatic journal bearing by monitoring bearing clearance. Adv. Mech. Eng. 2018, 10. [CrossRef]

15. Eberhardt, C.; Kurth, R.; Kraft, C.; Schwarze, H.; Päßler, T.; Bergmann, M.; Putz, M. Experimental validation of an intelligent hybrid plain bearing active control. J. Tribol. 2020, 143, 1-26. [CrossRef]

16. Rehman, W.U.; Jiang, G.; Wang, Y.; Iqbal, N.; Rehman, S.U.; Bibi, S.; Elahi, H. A new type of aerostatic thrust bearing controlled by high-speed pneumatic valve and a novel pressure transducer. Int. J. Automot. Mech. Eng. 2019, 16, 7430-7446. [CrossRef]

17. Kang, Y.; Yang, D.-W.; Hu, S.-Y.; Hung, Y.-H.; Peng, D.-X.; Chen, S.-K. Design for static stiffness of hydrostatic bearings: Double-action variable compensation of spool-type restrictors. Ind. Lubr. Tribol. 2014, 66, 83-99. [CrossRef] 
18. Kang, Y.; Peng, D.-X.; Hung, Y.-H.; Hu, S.-Y.; Lin, C.-S. Design for static stiffness of hydrostatic bearings: Double-action variable compensation of membrane-type restrictors and self-compensation. Ind. Lubr. Tribol. 2014, 66, 322-334. [CrossRef]

19. Babin, A.; Kornaev, A.; Rodichev, A.; Savin, L. Active thrust fluid-film bearings: Theoretical and experimental studies. Proc. Inst. Mech. Eng. Part J J. Eng. Tribol. 2020, 234, 261-273. [CrossRef]

20. Lai, T.-H.; Lin, S.-C. A simulation study for the design of membrane restrictor in an opposed-pad hydrostatic bearing to achieve high static stiffness. Lubricants 2018, 6, 71. [CrossRef]

21. Santos, I.F.; Scalabrin, A. Control system design for active lubrication with theoretical and experimental examples. J. Eng. Gas Turbines Power 2003, 125, 75-80. [CrossRef]

22. San Andrés, L.; Ryu, K. Hybrid gas bearings with controlled supply pressure to eliminate rotor vibrations while crossing system critical speeds. J. Eng. Gas Turbines Power 2008, 130. [CrossRef]

23. Sha, Y.; Lu, C.; Pan, W.; Chen, S.; Ge, P. Nonlinear control system design for active lubrication of hydrostatic thrust bearing. Coatings 2020, 10, 426. [CrossRef]

24. Ur Rehman, W.; Guiyun, J.; Yuan Xin, L.; Yongqin, W.; Iqbal, N.; UrRehman, S.; Bibi, S. Linear extended state observer-based control of active lubrication for active hydrostatic journal bearing by monitoring bearing clearance. Ind. Lubr. Tribol. 2019, 71, 869-884. [CrossRef]

25. Wang, C.; Cusano, C. Dynamic characteristics of externally pressurized, double-pad, circular thrust bearings with membrane restrictors. J. Tribol. 1991, 113, 158-165. [CrossRef]

26. Yan, Y.; Ding, L.; Yang, Y.; Liu, F. Discrete sliding mode control design for bilateral teleoperation system via adaptive extended state observer. Sensors 2020, 20, 5091. [CrossRef]

27. Tran, D.T.; Dao, H.V.; Dinh, T.Q.; Ahn, K.K. Output feedback control via linear extended state observer for an uncertain manipulator with output constraints and input dead-zone. Electronics 2020, 9, 1355. [CrossRef]

28. Deng, J.; Feng, C.; Zhao, H.; Wen, Y.; Wu, S. Disturbance and uncertainty suppression control for a saucer-shaped unmanned aerial vehicle based on extended state observer. Appl. Sci. 2020, 10, 4884. [CrossRef]

29. Lara, M.; Garrido, J.; Ruz, M.L.; Vázquez, F. Adaptive pitch controller of a large-scale wind turbine using multi-objective optimization. Appl. Sci. 2021, 11, 2844. [CrossRef]

30. Sánchez, H.S.; Padula, F.; Visioli, A.; Vilanova, R. Tuning rules for robust FOPID controllers based on multi-objective optimization with FOPDT models. ISA Trans. 2017, 66, 344-361. [CrossRef]

31. Zhou, X.; Zhou, J.; Yang, C.; Gui, W. Set-point tracking and multi-objective optimization-based PID control for the goethite process. IEEE Access 2018, 6, 36683-36698. [CrossRef]

32. Soleimani Amiri, M.; Ramli, R.; Ibrahim, M.F.; Abd Wahab, D.; Aliman, N. Adaptive particle swarm optimization of PID gain tuning for lower-limb human exoskeleton in virtual environment. Mathematics 2020, 8, 2040. [CrossRef]

33. Manikantan, R.; Chakraborty, S.; Uchida, T.K.; Vyasarayani, C. Parameter identification in nonlinear mechanical systems with noisy partial state measurement using PID-controller penalty functions. Mathematics 2020, 8, 1084. [CrossRef]

34. Mazen Alhato, M.; Bouallègue, S.; Rezk, H. Modeling and performance improvement of direct power control of doubly-fed induction generator based wind turbine through second-order sliding mode control approach. Mathematics 2020, 8, 2012. [CrossRef] 